\title{
BARREIRAS E FACILITADORES PARA A PARTICIPAÇÃO DE CRIANÇAS E ADOLESCENTES EM UM PROJETO SOCIOESPORTIVO'
}

\author{
DRA. DORALICE LANGE DE SOUZA \\ Doutora em Educação pela Harvard University \\ Professora do Setor de Ciências Biológicas da Universidade Federal do Paraná \\ (Curitiba - Paraná - Brasil) \\ E-mail: dora@ufpr.br
}

\begin{abstract}
MS. SUÉLEN BARBOZA EIRAS DE CASTRO
Mestre em Educação Física pela Universidade Federal do Paraná (Curitiba - Paraná - Brasil)

E-mail: sueleneiras@hotmail.com
\end{abstract}

\section{GRAD. ANDREA LEAL VIALICH}

Licenciada em Educação Física pela Universidade Federal do Paraná

Mestranda em Educação Física pela Universidade Federal do Paraná

(Curitiba - Paraná - Brasil)

E-mail: andrea@vialich.com

\begin{abstract}
RESUMO
O objetivo do trabalho foi o de investigar facilitadores e barreiras para a participação de crianças e adolescentes no projeto Esporte em Ação - Núcleo Vila Torres. A pesquisa foi qualitativa e os dados coletados através de observações e entrevistas com profissionais, participantes e pais/ responsáveis. Os principais facilitadores são: acesso ao esporte, a oportunidades educacionais e a um local mais seguro do que as ruas. As principais barreiras são: falta de segurança no trajeto até o projeto; falta de incentivos dos pais/responsáveis; clima; obrigações domésticas. A pesquisa oferece subsídios para o desenvolvimento de novos projetos e projetos similares.
\end{abstract}

PALAVRAS-CHAVE: Projeto social; crianças e adolescentes; determinantes; participação.

I. Pesquisa financiada pelo Ministério do Esporte, através da Rede CEDES, e pela UFPR, através do Programa Licenciar e do Programa de Iniciação Científica. 
Nas últimas décadas, o número de projetos sociais que envolvem o esporte e outras práticas corporais tem aumentado. Estes projetos, em sua maioria, têm sido desenvolvidos pelo governo, iniciativa privada, organizações não governamentais, dentre outras entidades, para atender crianças e adolescentes em situação de risco social, com o objetivo de ocupar o tempo livre dos mesmos, tirá-los das ruas e minimizar a sua vulnerabilidade à violência e ao uso de drogas (BRETÃS, 2007; GONÇALVES, 2003; GUEDES et al., 2006; MELO, 2007; SILVEIRA, 2007; THOMASSIM, 2007; VIANNA; LOVISOLO, 2009).

Em muitos casos, projetos sociais envolvendo o esporte têm sido percebidos enquanto verdadeiros "redentores da juventude pobre" (MELO, 2007, p. 57). O esporte, nestes projetos, não raramente, tem sido visto enquanto uma "salvação" para diferentes tipos problemas: "esporte para combater violência, para reduzir consumo de drogas, para manter as crianças na escola, para melhorar a saúde da população, para ser feliz" (LINHALES, 200I, p. 31). Embora muitas críticas possam ser tecidas a esta perspectiva "apologista" de projetos sociais que envolvem o esporte (THOMASSIM, 2006), uma vez que os mesmos não têm condições de solucionar problemas complexos como os acima, tais projetos podem exercer um importante papel na vida dos indivíduos que deles participam, bem como na vida dos pais e/ou responsáveis dos mesmos (SOUZA et al., 20 I0). Considerando-se o aumento de projetos sociais e o papel que os mesmos têm exercido no contexto brasileiro, estudos são necessários no sentido de avaliar o seu papel e melhor compreendê-los. Dentre possíveis problemáticas que poderiam ser investigadas neste sentido, elegemos pesquisar os fatores que determinam - barreiras e facilitadores - a participação de crianças e adolescentes nos mesmos.

Embora a literatura disponível sobre projetos sociais que envolvem o esporte e o lazer, de uma forma geral, não discuta diretamente a questão acima, os estudos disponíveis revelam, mesmo que indiretamente, possíveis facilitadores e barreiras para a participação nos mesmos. Em síntese, podemos inferir que a participação de crianças e adolescentes em projetos sociais que envolvem esporte e lazer está vinculada aos seguintes fatores: eles são espaços que possibilitam a sociabilização e aumento de vínculos sociais (ABRAMOVAY et al., 2003, 2006; GONÇALVES, 2003; MARQUES; KRUG, 2008; MENDES et al., 2007; MOLINA, 2007; SOUZA et al., 20 I0; VARGAS, 2007; ZALUAR, 1994); proporcionam acesso a atividades físicas e esportivas (GONÇALVES, 2003; MARQUES; KRUG, 2008; MENDES et al., 2007; MOLINA, 2007; SOUZA et al., 20I0; VARGAS, 2007; ZALUAR, 1994); oferecem acesso a um ambiente educacional (ABRAMOVAY et al., 2003; 
GONÇALVES, 2003; LEÃO, 2005; MARQUES; KRUG, 2008; MOLINA, 2007; VARGAS, 2007; ZALUAR, 1994); fornecem oportunidades de entretenimento, diversão e lazer no tempo livre (ABRAMOVAY et al., 2003, 2006; GONÇALVES, 2003; SOUZA et al., 2010; VARGAS, 2007; ZALUAR, 1994); são considerados espaços relativamente seguros quando comparados às ruas (ABRAMOVAY et al., 2003, 2006; LEÃO, 2005; MARQUES; KRUG, 2008; SOUZA et al., 20 I0; VARGAS, 2007); tiram crianças e adolescentes das ruas, ocupando o seu tempo livre e evitando o seu envolvimento com a criminalidade e drogas (GONÇALVES, 2003; GUEDES et al., 2006; MARQUES; KRUG, 2008; MENDES et al., 2007; MOLINA, 2007; VARGAS, 2007; ZALUAR, 1994); possibilitam perspectivas de profissionalização e de futuro através do esporte (GONÇALVES, 2003; GUEDES et al., 2006; MENDES et al. 2007; VARGAS, 2007; ZALUAR, 1994). Algumas das dificuldades apontadas por diferentes estudos, como barreiras para a implementação de projetos e programas sociais, podem também, direta ou indiretamente, se constituir em barreiras para a participação de crianças e adolescentes nos mesmos: carência de recursos materiais e equipamentos (ABRAMOVAY et al., 2003, 2006; LEÃO, 2005); falta de profissionais e carências de capacitação dos mesmos (ABRAMOVAY et al., 2003, 2006; LEÃO, 2005; SOUZA et al., 20 I0); falta de envolvimento de responsáveis por participantes (MENDES et al. 2007; ZALUAR, 1994), problemas de segurança (GONÇALVES, 2003; MELO, 2005; VIANNA; LOVISOLO, 2009); e o fato dos projetos dependerem, em grande parte, do trabalho de voluntários e/ou estagiários, o que não permite que se garanta a qualidade e/ou continuidade das atividades (ABRAMOVAY et al., 2003; SOUZA et al., 20 I0).

trabalho que apresentaremos a seguir teve como objetivo investigar os principais determinantes - barreiras e facilitadores - para a participação de crianças e adolescentes no Projeto Esporte em Ação - Núcleo Vila Torres, a partir da perspectiva de agentes envolvidos com o mesmo: responsáveis pelo projeto, professores, educadores, crianças e adolescentes, e pais/responsáveis. Escolhemos este projeto dado sua relevância social, uma vez que ele atende um número significativo de menores em um bolsão de pobreza em Curitiba, Paraná. Acreditamos que a investigação de fatores que facilitam e dificultam a participação de menores em projetos sociais pode gerar subsídios para o aprimoramento destes projetos e para o desenvolvimento de novos projetos que sejam de fato significativos para os seus participantes, e que lhes ofereçam condições concretas para o seu envolvimento nas atividades propostas.

\section{O PROJETO ESPORTE EM AÇÃO - NÚCLEO VILA TORRES}

Inaugurado em 2005, o projeto Esporte em Ação - Núcleo Vila Torres (EA-VT) é promovido pelo Instituto Compartilhar (IC) e pela Prefeitura Municipal 
de Curitiba, através da Fundação de Ação Social (FAS) e da Secretaria Municipal de Esporte e Lazer (SMEL). O EA-VT objetiva atender, principalmente, crianças e adolescentes entre oito e quinze anos, moradores da Vila Torres, em Curitiba. Esta vila tem aproximadamente 9.000 habitantes que, em grande parte, tem como principal fonte de renda a coleta de material reciclável (INSTITUTO COMPARTILHAR, [2005?]). As crianças e adolescentes atendidos pelo projeto estão inseridos no Programa de Erradicação do Trabalho Infantil (PETI), que é um programa do Governo Federal que tem como objetivo a erradicação do trabalho infantil, atendendo a crianças e adolescentes com idade inferior a 16 anos (BRASIL, [20 I0?]).

$\mathrm{O}$ EA-VT ocorre de segunda a sexta-feira, nos períodos da manhã e da tarde, na praça Plínio Tourinho. Durante o período em que coletamos os dados, além de oferecer um lanche para aproximadamente 90 crianças e adolescentes, promovia as seguintes atividades junto aos mesmos: voleibol, futebol de areia, capoeira, jogos alternativos, futsal, basquete, oficinas, palestras, apoio escolar, passeios, e outras atividades complementares organizadas por entidades parceiras (INSTITUTO COMPARTILHAR, [2005?]).

\section{DECISÕES METODOLÓGICAS}

A pesquisa foi de natureza qualitativa e de cunho exploratório, e os dados foram coletados entre junho e dezembro de 2009, através de entrevistas semiestruturadas e abertas na praça onde acontece o Esporte em Ação - Núcleo Vila Torres $(E A-V T)$. Realizamos uma entrevista semiestruturada com cada um dos participantes do estudo. Após uma análise prévia desta entrevista, nos casos em que percebemos a necessidade de maiores esclarecimentos, realizamos outra entrevista, desta vez aberta, para esclarecermos pontos que necessitavam de maiores explicações. Durante o trabalho de campo, realizamos também algumas observações assistemáticas. O objetivo das mesmas não era propriamente de coletar dados para respondermos o problema da pesquisa, mas sim o de contextualizar as questões das entrevistas e melhor conhecer a realidade do projeto.

Foram entrevistados seis crianças e adolescentes participantes do EA-VT, nove pais/responsáveis por crianças e adolescentes e treze profissionais das instituições envolvidas com o projeto. Os entrevistados do Instituto Compartilhar (IC) foram o gerente executivo, a psicóloga e quatro professores. Dentre os profissionais da Fundação de Ação Social (FAS), foram entrevistados a educadora responsável pelas crianças e adolescentes atendidos na praça, cinco educadores que trabalham diretamente com as crianças e adolescentes, e uma auxiliar de serviços gerais, que também é mãe de um dos participantes do projeto. As entrevistas com o gerente, 
professores e educadores foram feitas de forma individual e duraram em média sessenta minutos. As entrevistas com as crianças, adolescentes e pais/responsáveis também foram feitas individualmente e duraram entre cinco e trinta minutos. Tendo em vista que a proposta da pesquisa era de cunho exploratório, no caso das crianças e adolescentes, buscamos entrevistar um número equivalente de meninos e meninas de diferentes idades. No caso dos pais, entrevistamos apenas os que tivemos acesso no cotidiano do projeto e/ou que conseguimos agendar um encontro através da administração do programa. No caso dos profissionais, entrevistamos todos que concordaram em participar do estudo.

A análise foi baseada em procedimentos da teoria fundamentada (STRAUSS; CORBIN, 2008). Não utilizamos categorias determinadas a priori. As mesmas foram criadas a partir dos principais temas que emergiram das falas dos entrevistados, e foram alocadas em duas grandes áreas temáticas: "facilitadores" e "barreiras" para a participação no projeto. Este tipo de procedimento - o trabalho com temas emergentes - permite que os dados revelem o que é de fato essencial para a realidade estudada, sem a imposição de categorias e conceitos desenvolvidos em outros estudos e por outros autores. Ele também facilita a revelação de novos aspectos do fenômeno em voga, não tratados na literatura. Ou seja, ele permite que o processo de construção de conhecimento se dê a partir da realidade, por isto o nome "teoria fundamentada" ou "grounded theory". Uma vez que trabalhos produzidos a partir desta perspectiva são "enraizados" nos dados, estes tendem a gerar subsídios concretos para intervenção nas realidades estudadas (STRAUSS; CORBIN, 2008).

Para fins deste artigo, incluímos apenas os temas/categorias que surgiram como mais importantes para pelo menos dois grupos de sujeitos entrevistados (profissionais, crianças e adolescentes, e responsáveis pelas mesmas). Utilizaremos nomes fictícios femininos para garantir o anonimato dos profissionais envolvidos com o projeto, uma vez que foram poucos os homens que participaram da pesquisa, e, portanto, poderiam ser facilmente identificados caso utilizássemos também pseudônimos masculinos. Em algumas circunstâncias, principalmente quando discutimos a questão da violência na comunidade pesquisada, não citamos nem mesmo nomes fictícios, uma vez que os nomes reais de novos participantes do projeto podem vir a coincidir com os pseudônimos por nós criados. Isto poderia colocar em risco a segurança dos sujeitos de nossa pesquisa.

Esta pesquisa foi aprovada pelo Comitê de Ética da Universidade Federal do Paraná, (CAAE: 0012.0.091.000-09). O estudo foi legalmente autorizado pelos responsáveis pelas organizações envolvidas, e os participantes e/ou seus pais/responsáveis assinaram o Termo de Consentimento Livre e Esclarecido. 


\section{A OFERTA DE PRÁTICAS DESPORTIVAS}

A maioria dos menores entrevistados afirmou que a prática desportiva é o principal determinante para a sua participação no EA-VT. Os profissionais e responsáveis entrevistados igualmente percebem a prática desportiva como um grande atrativo do projeto. Outras pesquisas também apontam as atividades físicas e esportivas como um dos principais atrativos para a participação em projetos sociais (GONÇALVES, 2003; MARQUES; KRUG, 2008; MENDES et al., 2007; SOUZA et al., 20 I0; VARGAS, 2007; ZALUAR, 1994). Dentre as diferentes modalidades ofertadas, o futebol é a predileta.

Todo mundo quer futebol. [...] a procura deles maior é pelo futebol. [...] tem recreação e eles pedem pra jogar futebol. Tem um horário livre e eles pedem pra jogar futebol. Qualquer minutinho que eles têm é futebol não é vôlei, não é basquete. (Leticia, IC)

\section{O FATO DE O PROJETO SER PERCEBIDO COMO UM ESPAÇO MAIS SEGURO DO QUE AS RUAS}

Para boa parte dos participantes, todos os pais/responsáveis entrevistados e profissionais, o projeto é uma espécie de "porto seguro", que protege as crianças e adolescentes das ruas, onde estariam sujeitas à violência, más companhias e drogas.

Pra não ficar na rua [...]. Às vezes tem troca de tiro, né? Daí pode ser perigoso! (Michele, 12 anos)

É porque perto da minha casa tem briga de gangue e às vezes dá muito tiroteio, e eles ficando aqui, eu fico mais tranqüila [...]. Então é menos perigo. (Roberta, responsável)

E estando aqui eles estão mais seguros [...]. Se eles ficam na rua, [...] é perigoso, né? Fica aprendendo coisa que não [deve], né? Coisa que não presta! (Juliana, responsável)

A Vila enfrenta conflitos entre diferentes grupos de traficantes, o que gera preocupação com a segurança das crianças e adolescentes, seja por sua vulnerabilidade de envolvimento com a criminalidade e com as drogas, seja pelo risco dos mesmos serem atingidos por balas perdidas. Desta forma, muitos pais/responsáveis preferem que os mesmos participem do projeto a ficarem nas ruas. A percepção de que o espaço de projetos sociais é mais seguro do que as ruas é um facilitador para a participação de crianças e adolescentes também em outros projetos (ABRAMOVAY 
et al., 2003, 2006; LEÃO, 2005; MARQUES; KRUG, 2008; MENDES et al., 2006; SOUZA et al., 20 I0; VARGAS, 2007; ZALUAR, 1994).

Se, por um lado, a percepção do projeto como um "porto seguro" motiva a participação no EA-VT, o deslocamento até o mesmo não raramente se constitui em uma barreira para esta participação, dado a violência na Vila. Os moradores são identificados de acordo com o local onde residem e grupo de traficantes que domina cada área. O zoneamento das áreas de moradia, de acordo com o domínio de traficantes, impõe barreiras para a circulação das pessoas, inclusive das crianças e adolescentes, que temem se deparar com tiroteios em seu caminho para o EA-VT.

\footnotetext{
Existe uma divisão de poder dentro da Vila [...] que impedem em algum momento que as crianças se locomovam [...]. Então se estabeleceu ali: "Não deixe que o outro passe!", "Passou pra cá eu te mato!" [...] Então eu acho que esse é um grande desafio que extrapola a nossa capacidade. (profissional do IC)

E se aconteceu no fim de semana, vamos supor, tiroteio assim. Tem mãe que já prende mais, já não deixa que venha. Se o clima tá tenso, aí pode contar que vem bem menos crianças e as que vem, vem bem agitadas. Então varia muito de acordo com o ritmo ali [...]. Nessa Vila aqui é a violência que atrapalha, que é o principal fator assim que afeta. (profissional da FAS)
}

Mesmo diante de atividades interessantes, a prioridade é sempre a segurança das crianças e adolescentes.

Por mais que tenha qualquer coisa assim chamativa [...]. Pode fazer o que quiser [...] ninguém vai escolher, né? "Ah eu vou lá me divertir, vou lá ganhar isso ou vou fazer isso, mas eu tô colocando minha vida em risco! Primeiro eu vou defender a minha vida, né?" [...]. [Precisa de mais] segurança pra eles estarem vindo. (Denise, responsável)

Os estudos de Gonçalves (2003), Melo (2005), Vianna e Lovisolo (2009) também apontam o medo do confronto entre traficantes e de eventuais tiroteios e represálias como uma barreira importante para a participação da comunidade em projetos sociais.

\section{O FATO DE O PROJETO OFERECER UM AMBIENTE FAVORÁVEL À EDUCAÇÃO}

Tanto os pais/responsáveis pelas crianças e adolescentes quanto os profissionais que entrevistamos acreditam que o projeto oferece aos últimos uma oportunidade a mais de educação, tanto em termos de reforço escolar, quanto em termos de aprendizagem de valores e de novos conhecimentos e habilidades. 
Pelo menos não fica na rua, né? E aqui aprendem bastante coisa, aprendem o certo, aprendem o errado, aprendem o que pode fazer e o que não pode fazer, e isso é bom. (Roberta, responsável)

Alguns dizem assim: "A minha vó me manda pro projeto porque eu tenho muito o que aprender" [...]. Ele vem esteja chovendo, esteja o tempo que for, ele vem porque ele tem muito o que aprender. (Carla, FAS)

Segundo alguns entrevistados, o projeto ajudou a promover mudanças positivas em seus participantes:

Então depois que ele veio pro projeto, ele desenvolveu bastante. Agora ele tá 100\% melhor [...]. Antigamente ele não gostava de nada, ele brincava sozinho. E agora já não, ele se enturmou com as pessoas, já sabe brincar em grupo, então desenvolveu bastante. (Roberta, responsável)

O meu filho tinha uma época que ficava rebelde, né? Queria sair na rua com a piazada [molecada] pedir, sabe? [...] Não queriam participar de nada dentro de casa, era só na rua, daqui pra rua, rua, pra dentro de casa na hora de dormir [...]. Daí depois começou a mudar [...]. Esse fim de ano então, nem, nem, nem tem reclamação, no colégio também estão super bem. (Helena, responsável)

Outros estudos também apontam que a participação em projetos sociais é percebida enquanto um meio de educação (GONÇALVES, 2003; LEÃO, 2005; MARQUES; KRUG, 2008; ZALUAR, 1994) e desenvolvimento pessoal (ABRAMOVAY et al, 2003; VARGAS, 2007), bem como de promoção de um senso de responsabilidade e de bons comportamentos (MOLINA, 2007).

Para os responsáveis por crianças e adolescentes que participam do EA-VT, o projeto também é atrativo por oferecer às crianças e adolescentes oportunidades de encaminhamento profissional através de parcerias com outros projetos.

Completou 14 sai do projeto. É encaminhado pro menor aprendiz. Daí, isso que eu espero que ela vá. Eu quero ainda que ela faça na PUC. Porque ali é um lugar muito bom, né? (Marli, responsável)

A partir dos 14 anos a gente encaminha pro menor aprendiz [...]. Terminando o curso [...] a gente encaminha pro Pró-jovem [...]. Alguns pais têm essa visão que os filhos têm que estar aqui porque é uma oportunidade boa pra eles. (Sabrina, FAS)

Faz-se importante ressaltar que, embora exista a possibilidade de encaminhamento profissional após a saída do projeto, alguns dos entrevistados manifestaram 
a sua preocupação de que nem sempre isto é possível, dado à grande demanda e pouca oferta de vagas em propostas que possam atender aos interesses de todos os participantes.

\section{O CONTATO COM OS PAIS/RESPONSÁVEIS E O ENVOLVIMENTO DOS MESMOS COM O PROJETO}

O contato (ou falta) de contato com os pais e o envolvimento (ou falta de envolvimento) dos mesmos com o projeto afeta positivamente ou negativamente a participação das crianças e adolescentes no mesmo.

Os profissionais da FAS realizam visitas às famílias residentes na Vila Torres, tanto para convidar crianças e adolescentes em situação de trabalho infantil para participar do EA-VT, quanto para melhor conhecer a realidade daqueles que já participam do mesmo, com o objetivo de ajudá-los a superar dificuldades.

Temos plantão [...] pra gente estar fazendo visita [...] no final de semana estar indo atrás dos pais [...]. A partir do momento que a gente tá com cada adolescente, com cada criança, é uma família que vem junto com eles. Então é importante estar acompanhando [...]. A gente tem essa abertura de poder conversar com eles, e expor qualquer tipo de problema que a criança esteja passando aqui. (Sabrina, FAS)

As visitas às casas das famílias atuam, em muitos casos, como facilitadores para a participação de crianças e adolescentes no projeto.

Daí eles vai na casa da gente, né? Pede para matricular o filho, pra não ficar na rua e frequentando escola. Que se não ir na escola também não tem o projeto, né? Foi através da FAS. [...] Ela fez visita. Daí matriculei minhas meninas. (Marli, responsável)

Enquanto alguns pais/responsáveis incentivam a participação dos filhos no projeto, outros são omissos.

Existem alguns pais que são bastante colaboradores nossos no sentido de incentivar, não deixa que a criança fique em casa quando ele sai pra rua, e nesse sentido contribuem. Agora temos pais displicentes, principalmente os que são usuários de drogas, então esses não tão nem aí se a criança vem ou não vem. Geralmente vem, mas vem muito mal cuidados, sujos, então varia muito, né? Eu acho que temos sim pais bons, que colaboram conosco, mas temos os displicentes. [...] Tem pai que não liga muito pro filho. (Michele, FAS)

Apesar dos esforços dos profissionais da FAS para envolverem os pais/ responsáveis pelas crianças e adolescentes no projeto, são poucos os que de fato participam das reuniões e frequentam eventos que envolvem a família. 
A maioria dos pais trabalha fora o tempo inteiro, né? E tem filho pequeno, tem um monte de coisa. A maioria é carrinheiro. Então é complicado deles acharem um tempo pra vir pra cá. Até as reuniões que a gente faz, a última que a gente fez, que foi o dia da família, era pra ter cem famílias, tinha trinta. (Letícia, IC)

Se for doar alguma coisa, aparece bastante mãe. Quando é reunião, só reunião, aparece pouco. Então, às vezes a maioria vem mais pelo interesse de ganhar as coisas, e não participar do que, do que tá acontecendo. (Roberta, responsável)

Da mesma forma que o nosso estudo, uma pesquisa conduzida por Zaluar ( 1 994) também sugere que a participação de pais/responsáveis em projetos sociais é uma dificuldade. Como as atitudes dos adultos costumam interferir com os hábitos de crianças e adolescentes, estas tendem a interferir com a participação, dos últimos, nos projetos.

\section{OUTROS FATORES}

clima frio e chuvoso é uma das maiores barreiras para a frequência das crianças e adolescentes no EA-VT. Muitos não dispõem de agasalhos adequados para saírem de casa em dias muito frios. Existe também uma dificuldade de locomoção até a praça, devido a alagamentos. Quando chove nas residências, não raramente as crianças e adolescentes deixam de ir ao projeto for falta de roupas secas.

Às vezes, tá muito frio, alguns a gente sabe que não tem roupa pra vir, aí a mãe acaba deixando em casa. Aí, às vezes chove, molha tudo dentro de casa, molha a roupinha deles, eles não vêm. (Sabrina, FAS)

Outro fator que atrapalha a participação das crianças e adolescentes no EA-VT são as atividades de reforço escolar e/ou o envolvimento em outros projetos, que muitas vezes coincidem com os dias e horários do EA-VT.

No dia de reforço escolar eles não vêm [...]. Se eles tiverem reforço na escola, a gente não pode aceitar eles aqui, porque se eles foram pra aula de manhã, o reforço vai ser à tarde, então a gente não pode aceitar. (Marta, FAS)

Tem o reforço escolar também, por exemplo, chega final de bimestre, final de semestre, eles já começam a se apertar e começam a faltar, porque tem o reforço na escola. (Julia, IC)

Ainda outro problema enfrentado por algumas crianças e adolescentes é que precisam cuidar de irmãos mais novos. Devido a este fator, às vezes precisam faltar ou chegam atrasados nas atividades. 
São adolescentes que têm que levar o irmão na creche, por exemplo, depois da escola. Eé pra estar no projeto treze e trinta. De repente o irmão entra quinze pras duas na creche, na escola. Mas a gente daí entende isso e permite que até duas horas eles entrem. (Marta, FAS)

Ou então tem que cuidar do irmãozinho, a mãe pede pra ficar com alguém, né? Com o irmão mais novo e eles acabam ficando. (Isabela, IC)

Vianna e Lovisolo (2009) também concluíram que tarefas domésticas são barreiras para a participação de menores em projetos sociais.

\section{CONSIDERAÇÕES FINAIS}

Os principais facilitadores para a participação de crianças e adolescentes no projeto são: acesso à prática desportiva; o fato do projeto ser percebido como uma espécie de "porto seguro", que afasta os menores das ruas, da violência, das drogas e da criminalidade; a oferta de oportunidades educacionais; incentivos de pais e/ou responsáveis. Já as principais barreiras para a participação de crianças e adolescentes no EA-VT são: conflitos no bairro e falta de segurança no trajeto até a praça; falta de envolvimento e incentivos dos pais; clima frio e chuvoso; obrigações domésticas.

Projetos como o EA-VT podem se constituir em importantes meios de desenvolvimento e educação. No entanto, são ainda muitos os obstáculos para a participação de crianças e adolescentes nos mesmos. Uma alternativa para se estimular e viabilizar a participação, seria a instituição de parcerias entre escolas e organizações que se propõem a desenvolver projetos sociais, levando os projetos para o espaço escolar, como já acontece em alguns casos.

A instituição de parcerias entre projetos sociais e a escola, se respeitada a proposta político-pedagógica da mesma, poderia fortalecer o caráter educacional dos projetos. O desenvolvimento de projetos de contraturno dentro da própria instituição escolar poderia também facilitar a participação de crianças e adolescentes nas atividades, uma vez que os mesmos poderiam permanecer na escola o dia inteiro, não tendo que se deslocar para outro local, correndo determinados riscos, como os citados no decorrer deste trabalho. Idealmente, o Estado deveria assumir a responsabilidade pela educação de crianças e adolescentes em tempo integral. No entanto, até que este ideal se concretize, parcerias entre a escola e entidades tais como o Instituto Compartilhar podem se constituir em alternativas para a educação e lazer de crianças e adolescentes.

Para finalizar, gostaríamos de ressaltar a importância da realização de mais estudos sobre projetos sociais e outros programas de contraturno escolar. Os mesmos são necessários para que possamos gerar subsídios para o desenvolvimento de 
propostas que possam de fato atender as demandas da sociedade como um todo e, mais especificamente, as necessidades de crianças e adolescentes em situação de risco social.

Barriers and facilitators for the participation of children and adolescents in a sport's social project

ABSTRACT: The goal of this work was to investigate facilitators and barriers for the participation of children and adolescents in the project Esporte em Ação - Núcleo Vila Torres. The research was qualitative and the data was collected through observations and interviews with professionals, participants and parents/guardians of children and adolescents. The main facilitators are: access to sports, to educational opportunities and to a place safer than the streets. The main barriers are: lack of security in the way to the project, lack of incentives by parents/guardians; climate, domestic obligations. The research offers subsidies for the development of new and similar projects.

KEY WORDS: Social project; Children and adolescents; Determinants; Participation.

\section{Barreras y facilitadores para participación de niños y adolescentes en proyecto sociodeportivo}

RESUMEN: Este trabajo tuvo como objetivo investigar facilitadores y barreras para participación de niños y adolescentes en proyecto Esporte em Ação - Núcleo Vila Torres. La investigación tuvo carácter cualitativo, los datos fueron colectados de entrevistas con profesionales, participantes y responsables de menores. Los principales facilitadores son: acceso al deporte, oportunidad educativa y un local más seguro que las calles. Las principales barreras son: falta de seguridad hasta la plaza; falta de incentivos de padres/responsables, clima, obligaciones domésticas. La investigación ofrece ayuda al desarrollo de nuevos proyectos similares.

PALABRAS CLAVE: Proyecto Social; Niños y Adolescentes; Determinantes; Participación.

\section{REFERÊNCIAS}

ABRAMOVAY, M. et al. Avaliação do Programa Abrindo Espaços na Bahia. Brasília: UNESCO: Observatório de Violências nas Escolas, Universidade Católica de Brasília, UNIRIO, 2003. Disponível em: <http://unesdoc.unesco.org/images/00 I3/00 I3 13/131368por.pdf >. Acesso em: 12 fev. 2009.

Fazendo a diferença: Projeto Escola Aberta para a Cidadania no Estado do Rio Grande do Sul. Brasília: UNESCO: Secretaria da Educação do Rio Grande do Sul, 2006. Disponível em: < http://unesdoc.unesco.org/images/00 I 4/00 | 455// 4555 I por.pdf >. Acesso em: 12 fev. 2009.

BRASIL. Ministério do Desenvolvimento Social e Combate à Fome. Programa de erradicação do trabalho infantil (PETI). [20I0?]. Disponível em: <http://www.mds.gov.br/programas/ 
rede-suas/protecao-social-especial/programa-de-erradicacao-do-trabalho-infantil-peti>. Acesso em: 10 jun. 2009.

BRETÃS, A. Onde mora o perigo? Discutindo uma suposta relação entre ociosidade, pobreza e criminalidade. Educação, esporte e lazer. Boletim 09, junho 2007. Disponível em: <http://www.tvebrasil.com.br/salto/boletins2007/eel/0706 I I educacaoesporte.doc.> Acesso em: 23 abr. 2009.

GONÇALVES, M. A. R. A vila olímpica da verde-e-rosa. Rio de Janeiro: Ed. da FGV, 2003.

GUEDES, S. L. et al. Projetos sociais esportivos: notas de pesquisa. 2006. In: ENCONTRO REGIONAL DE HISTÓRIA, I2., 2006, Niterói. Anais... Rio de Janeiro: ANPUH, 2006. p. 92-92. Disponível em: <http://www.rj.anpuh.org/Anais/2006/conferencias/Simoni\%20 LGuedes,\%20Julio\%20Davies,\%20Michelle\%20ARodrigues\%20e\%20Rafael\%20MSantos. pdf>. Acesso em: 23 abr. 2009.

INSTITUTO COMPARTILHAR. Projeto Esporte em Ação. Curitiba, [2005?]. Disponível em: <http://www.compartilhar.org.br/prog_soc_espo_ctba.html>. Acesso em: 10 abr. 2009.

LEÃO, J. A. C. Considerações sobre o projeto escola aberta: perspectivas para uma agenda de lazer. 2005. 102 f. Dissertação (Mestrado em Gestão de Políticas Públicas) - Fundação Joaquim Nabuco, Instituto de Formação e Desenvolvimento Profissional, Recife. Disponível em: <http:// www.campus | 2.uneb.br/texto/artigos/escola_aberta.pdf>. Acesso em: 10 maio 2009.

LINHALES, M. A. Jogos da política, jogos do esporte: subsídios à reflexão sobre políticas públicas para o setor esportivo. In: MARCELLINO, N. C. (Org.). Lazer e esporte: políticas públicas. 2. ed. Campinas: Autores Associados, 2001 . p. 3 I-56.

MARQUES, M. N.; KRUG, H. N. As contribuições do Programa Segundo Tempo para os discentes de uma escola estadual de Santa Maria (RS): um estudo de caso fenomenológico. Revista Digital Ef Deportes, Buenos Aires, v. 13, n. I24, set. 2008. Disponível em: <http://mww.efdeportes.com/efd I 24/as-contribuicoes-do-programa-segundo-tempo.htm>. Acesso em: 08 jun. 2009.

MELO, M. P. Esporte e juventude pobre: políticas públicas de lazer na Vila Olímpica da Maré. Campinas: Autores Associados, 2005.

Esporte social futebol clube: contradições e dilemas em nosso tempo. Democracia Viva, n. 32, p. 54-58, jun 2007. Especial Pan 2007. Disponível em: <http://www.ibase.br/userimages/dv35_pan5.pdf>. Acesso em: 23 abr. 2009.

MENDES, V. R. et al. Como os pais percebem a participação dos filhos no Programa Segundo Tempo. In: CONGRESSO BRASILEIRO DE CIÊNCIAS DO ESPORTE, I5., Pernambuco. Anais... Recife: CBCE, 2007. Disponível em: < http://www.cbce.org.br/cd/resumos/265. pdf>. Acesso em: 23 abr. 2009.

MOLINA, R. K. Políticas de esporte e projetos sociais: impactos nos processos de subjetivação dos jovens. In: CONGRESSO BRASILEIRO DE CIÊNCIAS DO ESPORTE, I 5., Pernambuco. Anais... Recife: CBCE, 2007. Disponível em: < http://www.cbce.org.br/cd/resumos/278. pdf>. Acesso em: 23 abr. 2009. 
SILVEIRA, J. Desenvolvimento humano, responsabilidade social e educação no capitalismo: investigando o programa "Educação Pelo Esporte" do Instituto Ayrton Senna. 2007. I 5 I f. Dissertação (Mestrado em Educação Física) - Centro de Desportos da Universidade Federal de Santa Catarina, Florianópolis, 2007. Disponível em: < http://tede.ufsc.br/teses/PGEFO I 53. pdf>. Acesso em: 23 abr. 2009

SOUZA, D. L. de et al. Determinantes para a implementação de um projeto social. Motriz, Rio Claro, v. 16, n. 3, p. 689-700, jul./set. 20 I0. Disponível em: <http://www.periodicos. rc.biblioteca.unesp.br/index.php/motriz/article/view/l980-6574.20 I 0v l6n3p689/pdf_44>. Acesso em: 14 out. 2010.

STRAUSS, A.; CORBIN, J. Pesquisa qualitativa: técnicas e procedimentos para o desenvolvimento de teoria fundamentada. 2. ed. Porto Alegre: Porto Alegre, 2008.

THOMASSIM, L. E. C. Uma alternativa metodológica para a análise dos projetos sociais esportivos. 2006. In: EONCONTRO NACIONAL DE RECREAÇÃO E LAZER, I8., 2006, Curitiba. Anais... Curitiba: Ed. da PUCPR, 2006.

- Conflitos em torno do lazer: o sentido das práticas de responsabilidade social na contramão dos direitos sociais. In: SILVA, M. R. da (Org.). Esporte, educação, estado e sociedade. Chapecó: Argos, 2007. p. 257-28I.

VARGAS, L. S. Esporte, interação e inclusão social: um estudo etnográfico do "Projeto Esporte Clube Cidadão". 2007. I 19 f. Dissertação (Mestrado em Ciências Sociais) - Departamento de Ciências Sociais Aplicadas, Universidade do Vale do Rio dos Sinos, São Leopoldo, 2007. Disponível em: < http://bdtd.unisinos.br/tde_busca/arquivo.php?codArquivo=434>. Acesso em: 23 abr. 2009.

VIANNA, J. A.; LOVISOLO, H. R. Projetos de inclusão social através do esporte: notas sobre a avaliação. Movimento, Porto Alegre, v. 15, n. 3, p. 145-162, jul/set. de 2009. Disponível em: <http://www.seer.ufrgs.br/index.php/Movimento/article/view/5190/5583 >. Acesso em: 23 set. 2009.

ZALUAR, A. Cidadãos não vão ao paraíso. São Paulo: Escuta, 1994.

Recebido: 29 ago. 2010 Aprovado: I jul. 20 I I

Endereço para correspondência:

Doralice Lange de Souza Av. Senador Salgado Filho, I.800 casa II Curitiba, PR CEP: 8|5|0-00। 